\title{
Антибактериальная терапия при обострении хронической обструктивной болезни легких
}

ФГУ "НИИ пульмонологии ФМБА России": 105077, Москва, ул. 11-я Парковая, 32, к. 4

\author{
S.N.Avdeev
}

\section{Antibacterial therapy in acute exacerbation of chronic obstructive lung disease}

Key words: chronic obstructive lung disease, acute exacerbation, antibacterial therapy, biomarkers.

Ключевые слова: хроническая обструктивная болезнь легких, обострение, антибактериальная терапия, биомаркеры.

Хроническая обструктивная болезнь легких (ХОБЛ) заболевание, характеризующееся ограничением воздушного потока с развитием не полностью обратимой бронхиальной обструкции. Ограничение воздушного потока прогрессирует и связано с патологическим воспалительным ответом дыхательных путей на повреждающие частицы или газы [1]. Развитие обострений заболевания (увеличение выраженности симптомов) является характерной чертой течения ХОБЛ, их частота прогрессивно увеличивается с нарастанием тяжести заболевания [2].

В настоящее время обострение ХОБЛ определяется как "событие в течение заболевания, характеризующееся острым изменением имеющихся у пациента больного одышки, кашля и / или отделения мокроты по сравнению с обычным уровнем, которое выходит за рамки ежедневных колебаний, что является основанием для изменения плановой терапии по поводу ХОБЛ" [3, 4].

Обострение ХОБЛ является одной из лидирующих причин обращения больных за медицинской помощью [4]. Частое развитие обострений у больных ХОБЛ приводит к длительному ухудшению (до несколько недель) показателей функции дыхания и газообмена [5], более быстрому прогрессированию заболевания [6], к значимому снижению качеству жизни больных [7] и сопряжено с существенными экономическими расходами на лечение $[4,8]$. Более того, респираторные инфекции у больных ХОБЛ приводят к декомпенсации сопутствующих хронических заболеваний [9]. Тяжелое обострение заболевания является основной причиной смерти больных ХОБЛ $[10,11]$

Традиционная терапия обострений ХОБЛ включает в себя бронхорасширяющие препараты, глюкокортикостероиды и кислород и антибиотики [1]. Итак, попробуем ответить на следующие вопросы: почему и когда назначаются антибиотики при обострении ХОБЛ, какие препараты предпочтительны, и как долго они должны применяться?

\section{Почему назначаются антибиотики при обострении ХОБЛ?}

Основанием для назначения антибактериальных препаратов у больных с обострением ХОБЛ является ведущая роль бактериального фактора в генезе развития обострения.

Наиболее часто провоцируют обострение ХОБЛ инфекции трахеобронхиального дерева и атмосферные поллютанты [12, 13], однако примерно в 20$30 \%$ случаев причину установить не удается. Исследования с использованием бронхоскопических методов забора материала показали, что не менее чем у 50 \% больных с обострением можно выявить бактерии в нижних дыхательных путях в высокой концентрации [14, 15].

При обострении ХОБЛ наибольшую активность проявляют 3 микроорганизма: нетипируемые Haemophilus influenzae, Streptococcus pneumoniae и Moraxella catarrhalis (таблица) [12, 13, 16].

Исследования, в которых участвовали больные с тяжелым обострением ХОБЛ, показали, что у таких пациентов чаще могут встречаться грамотрицательные энтеробактерии и Pseudomonas aeruginosa (таблица) [17, 18]. Факторами риска инфицирования P. aeruginosa являются недавняя госпитализация, частое назначение антибиотиков ( $\geq 4$ за последний год), тяжелые обострения ХОБЛ и выделение P. aeruginosa в период предшествующего обострения или колонизация микроорганизма в стабильной фазе заболевания [19, 20].

Значение атипичных микроорганизмов (Мусоplasma pneumonia и Chlamydia pneumonia) в развитии обострения ХОБЛ, по-видимому, невелико (таблица). В ряде исследований острая инфекция $C$. pneumoniae была выявлена у 7-22 \% больных с обострением ХОБЛ [21, 22], а в некоторых - атипичные микроорганизмы вообще не были обнаружены [23].

Вирусные инфекции могут быть причиной 2530 \% всех случаев обострения ХОБЛ [24, 25]. Чаще все- 


\begin{tabular}{|c|c|c|c|}
\hline $\begin{array}{l}\text { Доля среди причин } \\
\text { обострений, \% }\end{array}$ & Возбудители & & Доля среди патогенов, \% \\
\hline \multicolumn{4}{|l|}{ Бактерии } \\
\hline \multirow[t]{8}{*}{$40-50$} & Нетипируемые Haemophilus influenzae & $20-30$ & \\
\hline & Streptococcus pneumoniae & $10-15$ & \\
\hline & Moraxella catarrhalis & $10-15$ & \\
\hline & Pseudomonas spp. & $5-10$ & $\begin{array}{l}\text { выделяют при тяжелом течении ХОБЛ, сопутствующих бронхоэктазах } \\
\text { и частых обострениях }\end{array}$ \\
\hline & Enterobacteriaceae & 5-10, & выделяют при тяжелом течении ХОБЛ и частых обострениях \\
\hline & Haemophilus parainfluenzae & & Выделяют часто, патогенетическое значение неясно \\
\hline & Haemophilus hemolyticus & & Выделяют часто, патогенетическое значение неясно \\
\hline & Staphylococcus aureus & & Выделяют нечасто, патогенетическое значение неясно \\
\hline \multicolumn{4}{|l|}{ Вирусы } \\
\hline \multirow[t]{6}{*}{$30-40$} & Риновирус & $20-25$ & \\
\hline & Вирус парагриппа & $5-10$ & \\
\hline & Вирус гриппа & $5-10$ & \\
\hline & Респираторно-синцитиальный вирус & $5-10$ & \\
\hline & Коронавирус & $5-10$ & \\
\hline & Аденовирус & $3-5$ & \\
\hline \multicolumn{4}{|l|}{ Атипичные бактерии } \\
\hline \multirow[t]{2}{*}{$5-10$} & Chlamydia pneumoniae & $3-5$ & \\
\hline & Mycoplasma pneumoniae & $1-2$ & \\
\hline
\end{tabular}

го выделяют риновирусы, вирусы гриппа, парагриппа и респираторно-синцитиальный вирус (таблица) $[17,26]$.

Рациональность использования антибиотиков при обострении ХОБЛ является предметом дискуссий [28]. Основной аргумент противников антибактериальной терапии (АБТ) - возможность спонтанного разрешения обострения: в процесс воспаления вовлекается только слизистая бронхов, и поэтому часто наступает спонтанная ремиссия обострения даже без этиотропной терапии [28]. Действительно, в некоторых исследованиях не было отмечено значительных различий в терапии антибиотиками и плацебо [29].

В одном из недавно выполненных метаанализов, включавшем в себя 13 рандомизированных контролируемых исследований (РКИ), было показано, что АБТ, по сравнению с плацебо, приводила к меньшему числу неудач терапии (отношение шансов (ОШ) $0,25)$ и была связана с более низкой летальностью (ОШ - 0,20) в группе больных с тяжелым обострением ХОБЛ, нуждавшихся в госпитализации в стационар [30]. Однако АБТ не снижала число неудач терапии у амбулаторных больных с легкими и среднетяжелыми обострениями ХОБЛ (ОШ - 1,09) [30].

В наиболее часто цитируемом рандомизированном плацебо-контролированном исследовании N.R.Anthonisen et al. также было показано, что благоприятный эффект АБТ при обострении ХОБЛ зависит, В первую очередь, от тяжести заболевания [31]. В данном исследовании у больных ХОБЛ с І типом обострения (наличие всех 3 кардинальных признаков обострения - усиления одышки, увеличения объема мокроты и повышения ее гнойности) терапия была успешной в $63 \%$ в группе больных, получавших ан- тибиотики, и в $43 \%$ - в группе плацебо $(p<0,05)$. В то же время обострения разрешилось успешно примерно с одинаковой частотой у больных с менее тяжелыми обострениями: при II типе обострения (наличие 2 кардинальных признаков) - 70 \% и $60 \%$ в группах терапии антибиотиками и плацебо, а также при III типе обострения (наличие 1 кардинального признака) - $74 \%$ и $70 \%$ соответственно (различия недостоверны).

Важные данные были получены в РКИ S.Noiura et al. [32]. В нем участвовали 93 больных ХОБЛ с острой дыхательной недостаточностью (ОДН), получавших респираторную поддержку. Оказалось, что 10-дневный курс терапии офлоксацином приводил к снижению летальности больных (4 \% vs $22 \%$ в группе плацебо; $p=0,01)$, длительности госпитализации $(14,9$ vs 24,5 дня; $p=0,01)$ и количества дополнительно назначенных антибиотиков (6\% vs $35 \%$ в группе плацебо; $p=0,0006)$.

Более того, в нескольких исследованиях было продемонстрировано, что АБТ при обострении ХОБЛ может уменьшить дальнейшую потребность в их назначении после выписки больных из стационара и увеличить время до следующего развития обострения у части больных ХОБЛ [33, 34].

В ретроспективном исследовании, в котором анализировались 363 обострения ХОБЛ в течение 18 мес., АБТ, по сравнению с отсутствием терапии антибиотиками, приводила к снижению числа рецидивов обострений в последующие 2 нед. (32\% vs $19 \%$; $p<0,001)[35]$.

В недавно опубликованном исследовании B.M.Roede et al. проанализированы те же самые эффекты АБТ у амбулаторных больных с обострением ХОБЛ $(n=842)$ [36]. АБТ в период обострения приводила 
к удлинению интервала между обострениями: 189 vs 258 дней $(p<0,01)$. Долгосрочная летальность была существенно ниже в группе больных ХОБЛ, получавших АТБ во время обострения: $14 \%$ vs $20 \%$ ( $p=$ 0,02). Выводы данного исследования имеют важное значение, т. к. впервые было продемонстрировано, что АБТ оказывает благоприятный эффект не только при тяжелом обострении ХОБЛ, но и при более легком - в тех случаях, когда антибиотики назначаются больным в амбулаторных условиях.

Таким образом, АБТ не только ускоряет разрешение обострения ХОБЛ и улучшает функциональные показатели, но и улучшает прогноз при тяжелой его форме.

\section{Когда при обострении ХОБЛ назначать антибиотики?}

Учитывая имеющиеся в настоящее время доказательства [37], антибиотики следует назначать:

- пациентам с обострением ХОБЛ, имеющим 3 кардинальных признака Anthonisen - усиление одышки, увеличение объема мокроты и усиление гнойного характера мокроты;

- пациентам с обострением ХОБЛ, имеющим 2 кардинальных признака обострения, если один из этих 2 симптомов - усиление гнойного характера мокроты;

- пациентам с тяжелым обострением ХОБЛ, нуждающимся в инвазивной или неинвазивной вентиляции легких.

\section{Значение усиления продукции гнойной мокроты при обострении ХОБЛ}

Одним из наиболее важных исследований, где была показана высокая диагностическая ценность такого признака, как усиление гнойного характера мокроты, явилась работа R.A.Stockley et al. [38]. У 121 амбулаторного больного ХОБЛ проводилось изучение мокроты (внешний вид, окраска по грамму, микроскопия, посев) как во время обострения, так и через 2 мес. после него. Положительный рост бактерий был выявлен у $84 \%$ больных с гнойной мокротой и у $38 \%$ пациентов - со слизистой $(p<0,0001)$. Кроме того, в гнойной мокроте, по сравнению со слизистой, была более выражена нейтрофилия, чаще бы-

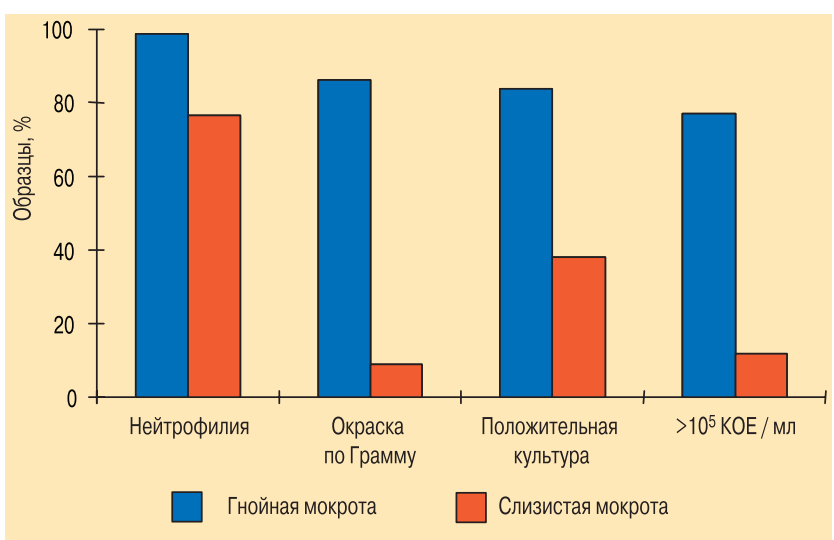

Рис. 1. Распределение больных с обострением ХОБЛ в зависимости от типа мокроты [38] ли получены положительные результаты при окраске по Граму и была более высокой бактериальная нагрузка (рис. 1). Наличие гнойной мокроты отражало высокую бактериальную нагрузку в дыхательных путях больных с чувствительностью 94,4 \% и специфичностью 77,0 \% и позволяло выявить больных, подходящих для проведения АБТ.

N.Soler et al. провели исследование, в котором у 40 больных с обострением ХОБЛ, госпитализированных в отделение интенсивной терапии, изучали клинические маркеры бактериальной природы данного состояния, используя метод количественного культурального исследования материала, полученного во время бронхоскопии с помощью защищенной щеточной биопсии (ЗЩБ) [39]. У всех больных ХОБЛ были также взяты для микробиологического исследования образцы спонтанно откашливаемой мокроты. У 77 \% пациентов, сообщивших о наличии гнойной мокроты, были обнаружены бактериальные патогены в материале, полученном при ЗЩБ. Чувствительность жалоб пациента на наличие гнойной мокроты составила 89,5 \%, специфичность - 76,2 \%. Наличие гнойной мокроты, о котором сообщают больные, является значимым предиктором бактериальной природы обострения.

По данным исследования, в котором участвовали больные с обострением ХОБЛ, нуждающиеся в инвазивной или неинвазивной вентиляции легких, отказ от терапии антибиотиками сопровождался ростом смертности и более высокой частотой развития вторичной внутрибольничной пневмонии [32]. С учетом непосредственной угрозы жизни при развитии ОДН на фоне ХОБЛ такие пациенты должны получать антибиотики, т. к. устранение причинного фактора ОДН помогает улучшить прогноз [40].

Опасения относительно недостаточной аккуратности существующих подходов к диагностике бактериальных инфекций и невозможность при использовании такой стратегии избежать чрезмерного назначения антибактериальных препаратов привело к более широкому использованию биомаркеров, что может позволить улучшить диагностику и подходы к терапии обострений ХОБЛ. К числу таких биомаркеров относятся С-реактивный белок (СРБ) и прокальцитонин (ПКТ) [41].

У больных с бактериальной легочной инфекцией происходит быстрое повышение концентрации в сыворотке крови предшественника гормона кальцитонина - ПКТ [42], который высвобождается из нейроэндокинных клеток бронхиального эпителия и / или мононуклеарных клеток [43, 44]. У здоровых людей концентрация сывороточного ПКТ очень низка и составляет 0,01 нг/мл. При вирусных инфекциях уровень ПКТ повышается мало, редко достигая 1 нг/мл [45].

В основу исследования D.Stolz et al. была положена гипотеза о том, что концентрация ПКТ в сыворотке крови может использоваться для определения показаний к назначению АБТ при обострении ХОБЛ [46]. Для проверки этой гипотезы было проведено проспективное рандомизированное исследова- 
ние по сравнению лечения обострения ХОБЛ, основанного на существующих руководствах, и терапии, определяемой уровнем ПКТ.

В исследование были включены госпитализированные пациенты с обострением ХОБЛ. При поступлении они рандомизировались на 2 группы: 1) группу стандартной терапии, в которой лечащий врач на основании существующих руководств определял показания к АБТ; 2) группу РСТ, в которой показания к АБТ определялись на основании концентрации ПКТ. Уровень ПКТ $<0,1$ нг/мл исключал наличие бактериальной инфекции и назначение антибиотиков, уровень РСТ от 0,10 до 0,25 нг/мл свидетельствовал о возможной бактериальной инфекции (назначение антибиотиков зависело от состояния пациента), концентрация РСТ > 0,25 нг/мл расценивалась как бактериальная инфекция, и назначение антибиотиков считалось обоснованным.

В исследовании участвовали 208 пациентов, все они находились под наблюдением в течение 6 мес. или до момента смерти. При поступлении концентрация ПКТ < 0,1 нг/мл была обнаружена у $51 \%$ больных, от 0,10 до 0,25 нг/мл - у $29 \%$ и > 0,25 нг/мл у $20 \%$ пациентов. Назначение лечения на основании концентрации ПКТ значимо уменьшило частоту применения антибактериальных препаратов (40\% vs $72 \%$ ), относительный риск (ОР) приема антибактериальных препаратов в группе ПКТ составил 0,56. Частота курсов антибиотиков в следующие 6 мес. значимо не различалась между группами (46 vs 43 курсов). Между группами ПКТ и стандартного лечения не было различий в частоте клинического успеха терапии обострения $(82,4 \%$ vs $83,9 \%)$, частоте обострений $(0,62$ vs 0,64$)$ и частоте госпитализаций по поводу ХОБЛ $(0,21$ vs 0,24$)$ и летальности $(5$ vs 9 больных; $p=0,409)$ в течение 6 мес.

Таким образом, данное исследование показало, что при обострении ХОБЛ использование стратегии АБТ на основе уровня ПКТ ведет к снижению числа назначений антибактериальных препаратов без ущерба для клинического успеха лечения и времени

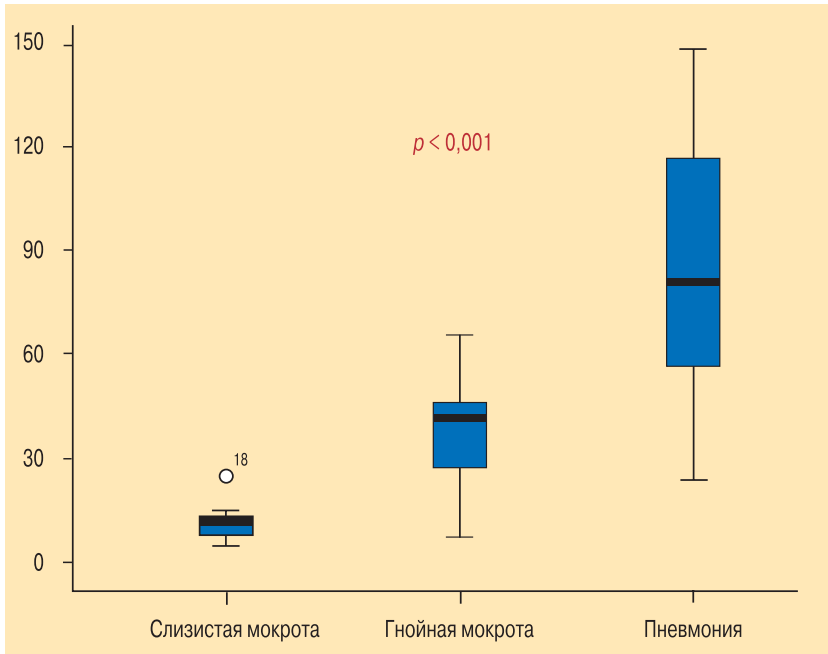

Рис. 2. Уровни СРБ при обострении ХОБЛ у больных со слизистой, гнойной мокротой и с пневмонией [55] до развития следующего обострения, а также без повышения необходимости повторного назначения антибиотиков в последующие 6 мес.

СРБ относится к семейству плазменных белков пентаксина и является $\alpha_{2}$-глобулином [47]. В условиях воспаления, инфекции либо повреждения тканей плазменный СРБ синтезируется преимущественно гепатоцитами под контролем провоспалительных цитокинов, главным образом интерлейкина-6 и, в меньшей степени, интерлейкина-1 и фактора некроза опухоли- $\alpha$ [48-50]. У практически здоровых лиц содержание СРБ в сыворотке крови не превышает 10 мг/л [51, 52].

О ценности СРБ как биомаркера обострения ХОБЛ свидетельствуют результаты исследования J.R.Hurst et al., в котором сравнивались чувствительность и специфичность 36 различных биомаркеров у 90 больных с обострением ХОБЛ [53]. Оказалось, что, по сравнению со всеми изученными маркерами, наибольшей диагностической ценностью обладал хорошо известный СРБ, для него площадь под ROCкривой составила 0,73 .

В работе D.Dev et al. уровень СРБ > 10 мг/л был зарегистрирован у всех больных с доказанным инфекционным обострением ХОБЛ (среднее значение $-103 \pm 98$ мг/л). Сывороточный уровень СРБ коррелировал с лейкоцитозом периферической крови $(r=0,44 ; p<0,01)$ и снижался на фоне лечения антибиотиками [54].

В исследовании, проведенном в НИИ пульмонологии (Москва), приняли участие 123 пациента, госпитализированных в стационар с обострением ХОБЛ $[55,56]$. Концентрация СРБ сыворотки крови у пациентов с ХОБЛ и пневмонией была значительно выше, чем у больных с обострением ХОБЛ и гнойной и слизистой мокротой $(105,8 \pm 66,1 \mathrm{vs}$ $34,5 \pm 18,8$ vs 12,1 \pm 7,0 мг/л соответственно; $p<$ 0,001; рис. 2). У 42,3 \% пациентов без увеличения гнойности мокроты уровень СРБ был нормальным, у больных с продукцией гнойной мокроты нормальное значение СРБ встречалось лишь в 5,4 \% случаев. Пороговый уровень СРБ $\geq 16,5$ мг/л при обострении ХОБЛ для диагностики бактериальной инфекции имел чувствительность $93 \%$, специфичность - $93 \%$.

\section{Какие антибиотики назначать при обострении ХОБЛ?}

В подавляющем большинстве случаев АБТ при обострении ХОБЛ является эмпирической [57] и должна основываться на местных эпидемиологических данных о структуре возбудителей и их чувствительности к антимикробным препаратам. На основании факторов риска, возраста, функциональных особенностей больных было предложено несколько классификационных схем обострения ХОБЛ, позволяющих рекомендовать несколько режимов терапии (рис. 3) [57]. С помощью данной классификации можно оптимально предположить причинный фактор и значительно снизить шанс неуспешной терапии обострения ХОБЛ. 
Авдеев С.Н. Антибактериальная терапия при обострении хронической обструктивной болезни легких

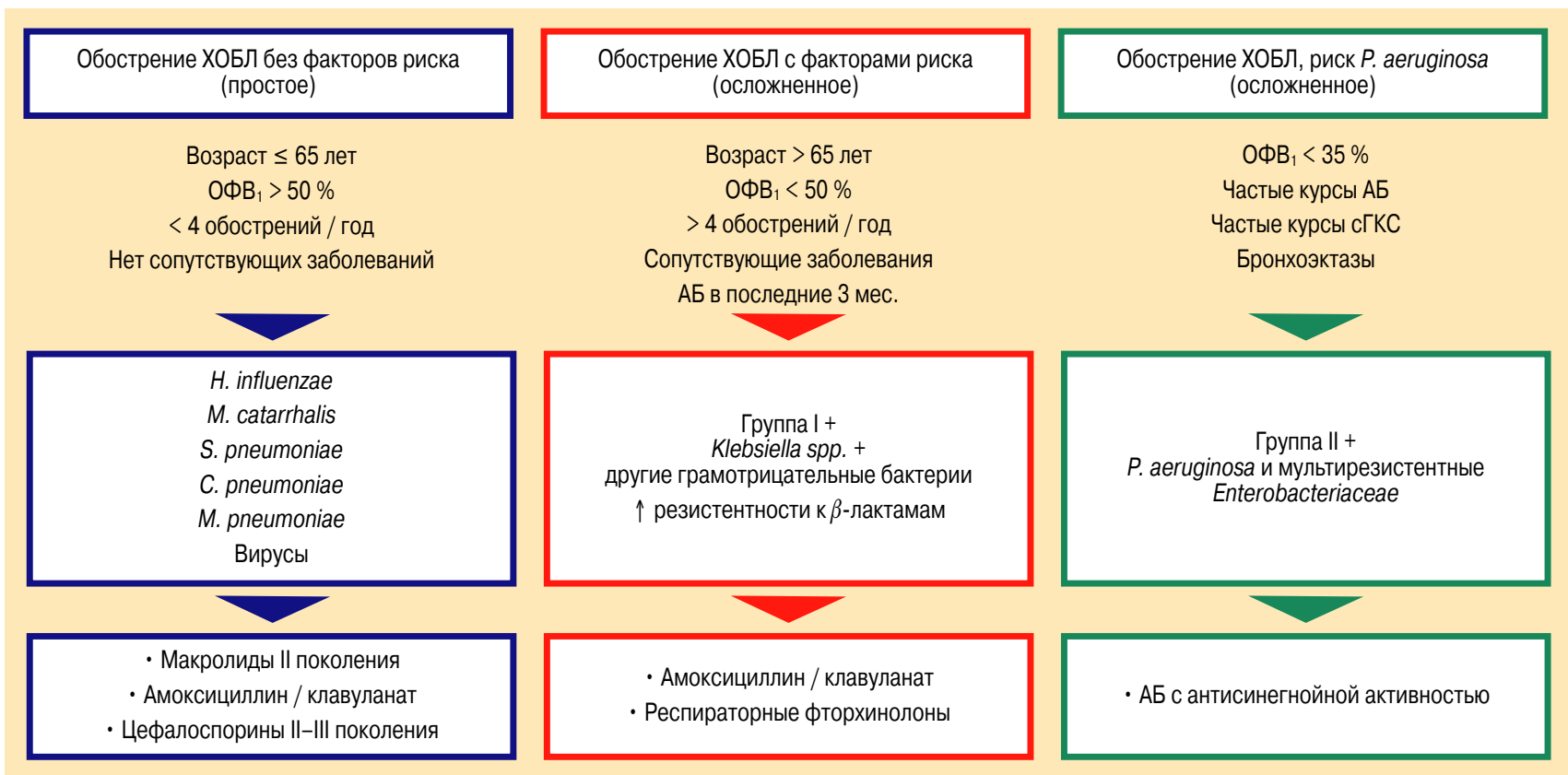

Рис. 3. Антибактериальная терапия при обострении ХОБЛ

К факторам риска развития тяжелых обострений ХОБЛ относятся выраженность бронхиальной обструкции, возраст больных, сопутствующие заболевания и тяжесть симптомов при развитии обострения [31, 32, 58-60]. Однако большинство из них были выявлены в различных ретроспективных исследованиях и не были валидизированы в проспективных рандомизированных исследованиях.

В работе N.R.Anthonisen et al. использовались несколько антибиотиков (триметоприм / сульфаметоксазол, амоксициллин и доксициклин), причем считалось, что выбор препарата не имеет большого значения, т. к. все выбранные средства примерно равноценны [31]. Кроме того, большинство проведенных исследований, посвященных сравнению антибактериальных препаратов при обострении ХОБЛ, имели цель показать эквивалентность нового препарата старому, но выбор препарата сравнения также не считался важным. Однако, поскольку спектр активности в отношении основных респираторных возбудителей и картина антибактериальной резистентности при использовании разных препаратов отличаются, выбор антибиотика может иметь важное значение для успешной терапии обострения ХОБЛ.

В метаанализе G.Dimopoulos et al., основанном на 12 РКИ, изучалось сравнение эффективности и безопасности традиционных или "старых" антибиотиков (амоксициллина, ампициллина, пивампициллина, триметоприма / сульфаметоксазола и доксициклина) и современных, "новых" препаратов (макролидов, фторхинолонов, амоксициллина / клавуланата и цефалоспоринов II и III генераций) у больных с обострением ХОБЛ [61]. Оказалось, что терапия "старыми" антибиотиками была менее эффективна в клиническом отношении, по сравнению с "новыми" препаратами (ОШ - 0,51; 95\%-ный доверительный интервал (ДИ) - 0,34-0,75), однако не было выявлено достоверных различий в летальности (ОШ - 0,64; 95\%-ный ДИ - 0,25-1,66) или количестве побочных эффектов (ОШ - 0,75; 95\%-ный ДИ - 0,39-1,45) [61].

В настоящее время основное значение для терапии обострений ХОБЛ имеют 3 группы антибактериальных препаратов: макролиды, фторхинолоны, и амоксициллин / клавуланат.

Метаанализ I.I.Siempos et al., основанный на 19 РКИ (7 405 больных), был посвящен сравнению эффективности и безопасности макролидов, хинолонов и амоксициллина / клавуланата при лечении больных с бактериальным обострением ХОБЛ / хронического бронхита (ХБ) [62]. Данный анализ показал, что клиническая эффективность АБТ практически не различалась между группами пациентов, получавшими макролиды и хинолоны (ОШ - 0,94; 95\%-ный ДИ - 0,73-1,21), амоксициллин / клавуланат и хинолоны (ОШ - 0,86; 95\%-ный ДИ 0,55-1,34), амоксициллин / клавуланат и макролиды (ОШ - 1,70; 95\%-ный ДИ - 0,72-4,03). Однако бактериологическая эффективность оказалась достоверно ниже у больных, принимавших макролиды, по сравнению с больными, получавшими хинолоны (ОШ - 0,47; 95\%-ный ДИ - 0,31-0,69). У больных, принимавших хинолоны, по сравнению с пациентами, получавшими макролиды, реже наблюдались рецидивы обострения ХОБЛ в течение 26 нед. после окончания АБТ.

\section{Макролиды}

Эффективность и безопасность макролидов при инфекциях нижних дыхательных путей подтверждается результатами многочисленных клинических исследований и метаанализов [63]. Они хорошо проникают в бронхиальный секрет, слизистую и легочную ткань, создавая в них концентрацию, значительно превышающую таковую в сыворотке крови. К досто- 
инствам современных макролидов относятся низкая токсичность и хорошая переносимость, включая невысокий аллергогенный потенциал [64]. В России уровень устойчивости к макролидам $S$. pneumoniae составляет $<7 \%$ [65].

Слабым местом макролидов при лечении обострения ХОБЛ является их низкая активность по отношению к $H$. influenzae. Несмотря на то, что во многих сравнительных исследованиях была показана неплохая клиническая и бактериологическая эффективность макролидов, в т. ч. II поколения (азитромицина и кларитромицина), при обострении ХОБЛ и ХБ [66-69], следует помнить, что в основном это были больные с нетяжелым обострением, у которых высока вероятность спонтанного улучшения [31], а доля $H$. influenzae среди патогенов, вызвавших обострение ХОБЛ, относительно мала [70]. Кроме того, определенный вклад в клиническую эффективность макролидов могут вносить их противовоспалительные и иммуномодулирующие свойства [71].

По данным последней версии "Экспертных правил по тестированию антимикробной чувствительности" (2008), разработанных European Committee on Antimicrobial Susceptibility Testing, H. influenzae обладает природной резистентностью к макролидам [72].

\section{Респираторные фторхинолоны}

K современным перспективным препаратам для терапии больных с обострением ХОБЛ относятся респираторные фторхинолоны (левофлоксацин, моксифлоксацин, гемифлоксацин). В отличие от лекарственных средств более ранних генераций (офлоксацина, ципрофлоксацина), они обладают высокой активностью по отношению к $S$. pneumoniae, включая и мультирезистентные штаммы [73]. При этом респираторные фторхинолоны сохраняют высокую активность и по отношению к грамотрицательным микроорганизмам (в т. ч. H. influenzae и M. catarrhalis) и внутриклеточным патогенам [74]. Установлено, что левофлоксацин в дозе 750 мг/с достаточно эффективен против синегнойной палочки [75].

Респираторные фторхинолоны имеют привлекательные фармакокинетические свойства: способность к высокой концентрации в слизистой бронхов и мокроте, высокую биодоступность (70-95 \%) [74]. Наличие пероральной и парентеральной лекарственных форм у левофлоксацина и моксифлоксацина позволяет использовать их в ступенчатой терапии.

По данным многоцентрового проспективного исследования ПеГАС-II, проведенного в России в 2003-2005 гг., все исследованные штаммы $S$. pneumoniae были чувствительны к левофлоксацину и моксифлоксацину, независимо от резистентности к другим антимикробным препаратам [76].

\section{Амоксициллин / клавуланат}

В качестве препаратов выбора при обострении многие современные руководства рассматривают аминопенициллины, в т. ч. защищенные ингибиторами $\beta$-лактамаз $[1,37,77]$. Наиболее изученный препарат из группы защищенных пенициллинов - комбина- ция амоксициллина и клавулановой кислоты (амоксициллин / клавуланат). Он характеризуется высокой биодоступностью при приеме внутрь, хорошим проникновением в различные ткани и жидкости организма, что позволяет достигать в них концентраций антибиотика, многократно превосходящих значения минимальной подавляющей концентрации для чувствительных микроорганизмов.

Добавление к амоксициллину ингибитора $\beta$-лактамаз клавулановой кислоты привело к значительному расширению спектра антибактериальной активности препарата за счет грамотрицательных возбудителей, способных к продукции $\beta$-лактамаз (H. influenzae, M. catarrhalis), некоторых энтеробактерий (K. pneumoniae и др.), метициллино-чувствительных штаммов $S$. aureus и неспорообразующих анаэробов [78].

Российские мультицентровые исследования ПеГАС-I и -II показали, что в РФ в 1999-2005 гг. доля штаммов $S$. pneumoniae, устойчивых к аминопенициллинам, составляла всего $0,1 \%$, а уровень резистентности к ампициллину штаммов $H$. influenzae $5 \%$. При этом не было выявлено штаммов, резистентных к амоксициллину / клавуланату [65].

В исследовании Л.И.Дворецкого проводилось сравнение микробиологической и клинической эффективности амоксициллина / клавуланата и макролидов (азитромицина и кларитромицина) у 40 больных с обострением ХОБЛ. Бактериологическую оценку выполняли через 3-5 дней после окончания терапии, а клиническую эффективность препаратов определяли на основании темпов регрессии симптомов обострения ХОБЛ и длительности безрецидивного периода на протяжении 12-месячного срока наблюдения [79]. Эрадикация бактериальных патогенов после окончания терапии амоксициллином / клавуланатом была достигнута у $92 \%$ больных, после терапии макролидами - у $30 \%$, персистенция возбудителей регистрировалась у $8 \%$ и 70 \% пациентов соответственно. На фоне терапии амоксициллином / клавуланатом быстрее регрессировали симптомы обострения, по сравнению с лечением макролидами. Очередное обострение ХОБЛ после отмены АБТ наступало на протяжении 12 мес. наблюдения у 57,9 и $88,9 \%$ ( $p \leq 0,05)$ больных, получавших во время обострения амоксициллин / клавуланат или макролиды соответственно. Средняя продолжительность ремиссии у больных, принимавших амоксициллин / клавуланат и макролиды, составляла $263 \pm 107$ и $165 \pm$ 112 дней соответственно.

Недостатком амоксициллина / клавуланата является относительно высокий риск развития нежелательных лекарственных реакций (НЛР) [62]. Наиболее частый побочный эффект данного препарата неблагоприятное действие клавулановой кислоты на слизистую оболочку органов пищеварения, что может привести к развитию диареи и стать причиной преждевременного прекращения АБТ (в 9 \% случаев) [80]. Показано, что частота диареи зависит и от вариабельности всасывания препарата. Чем больше клавулановой кислоты усваивается в кишечнике, 


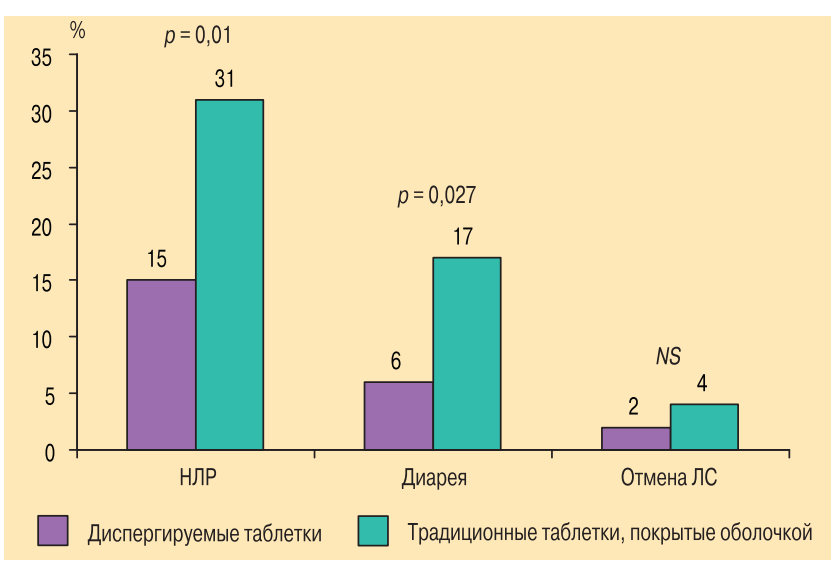

Рис. 4. Побочные эффекты при использовании препаратов амоксициллина / клавуланата при инфекциях нижних дыхательных путей [84]

$N S$ - различия недостоверны.

тем меньше ее остаточное токсическое действие на слизистую оболочку [81].

Одним из возможных путей снижения потенциала НЛР при приеме амоксициллина / клавуланата может быть использование лекарственных форм, обеспечивающих более полное всасывание активных ингредиентов препарата из желудочно-кишечного тракта - диспергируемых таблеток (технология Солютаб) [82]. При использовании диспергируемых таблеток отмечена более быстрая и полная абсорбция клавулановой кислоты в кишечнике по сравнению с традиционной формой амоксициллина / клавуланата (таблетки, покрытые оболочкой) [83]. Более быстрое всасывание препарата обеспечивает не только меньшее раздражающее действие на слизистую желудочно-кишечного тракта и проявление наиболее благоприятного антибиотического эффекта, но и значительное уменьшение времени нахождения амоксициллина в кишечнике, а следовательно, сводит к минимуму его негативное действие на кишечную микрофлору [81].

В открытом проспективном рандомизированном исследовании И.А.Гучева и Р.С.Козлова у взрослых больных с инфекциями нижних дыхательных путей проводилось сравнение безопасности и эффективности различных лекарственных форм амоксициллина / клавуланата - диспергируемых таблеток (Флемоклава) и обычных таблеток, покрытых оболочкой (Аугментина) [84]. Оба препарата назначались внутрь в дозе 500 / 125 мг 3 раза в день в течение 5-12 дней. В исследование были включены 200 больных с нетяжелой внебольничной пневмонией и обострением ХОБЛ І и II типа по Anthonisen. Пациенты в группах терапии были сопоставимы по своим демографическим данным, тяжести и характеру течения заболевания.

Средняя длительность АБТ не различалась между группами Флемоклава и Аугментина и составляла $7,1 \pm 1,5$ сут. и 7,2 $\pm 1,4$ сут. соответственно. Клиническая эффективность среди больных, получавших разные режимы АБТ, оказалась очень высокой, и в конце курса (5-12-й дни) составила $97 \%$ и $97 \%$, через 30-40 дней - 96 \% и 97 \% в группах Флемоклава и Аугментина соответственно. Однако значительные различия между группами терапии были выявлены по общему числу нежелательных лекарственных реакций: $15 \%$ vs 31 \% в группах приема амоксициллина / клавуланата в виде диспергируемых и обычных таблеток соответственно ( $p=0,01$; рис. 4). У больных, получавших диспергируемые таблетки амоксициллина / клавуланата, выявлена меньшая частота развития диареи - $6 \%$ vs $17 \%(p=0,027)$. Преждевременная отмена исследуемого препарата вследствие развития нежелательных лекарственных реакций также была в 2 раза реже у пациентов данной группы $-2 \%$ vs $4 \%(p>0,05)$.

Таким образом, несмотря на то, что оба препарата амоксициллина / клавуланата продемонстрировали высокую и эквивалентную клиническую эффективность при нетяжелых инфекциях нижних дыхательных путей, лекарственная форма в виде диспергируемых таблеток характеризовалась лучшим профилем безопасности по сравнению с оригинальным амоксициллином / клавуланатом, что проявлялось уменьшением частоты встречаемости нежелательных явлений, особенно диареи.

\section{Какова оптимальная продолжительность АБТ при обострении ХОБЛ?}

Согласно последней версии рекомендаций GOLD, на основании результатов проведенных исследований при обострении ХОБЛ следует применять антибиотики в течение 3-7 дней [1].

Возможность использования 5-дневных курсов АБТ была продемонстрирована в РКИ для таких препаратов, как амоксициллин / клавуланат (2 000 / 125 мг) [85], цефдиторен [86], левофлоксацин [69], моксифлоксацин [33, 87], гемифлоксацин [88, 88], азитромицин [69] и телитромицин [90].

Короткие курсы (3-5 дней) АБТ, по сравнению с "традиционными" продолжительными, гарантируют более высокий комплаенс больных, особенно в амбулаторных условиях [91, 92]. Для пациентов, принимающих антибиотики, пропуск их приема или незапланированное прерывание курса означают не только снижение эффективности терапии, но повышение вероятности "селекции" резистентных микроорганизмов [91].

R. El Moussaoui et al. выполнили метаанализ 21 РКИ (10 698 больных) для оценки эффективности коротких курсов антибиотиков ( $\leq 5$ дней) по сравнению с длительными ( $>5$ дней) у пациентов с обострением ХОБЛ / ХБ І-ІІ типа, по N.R.Anthonisen [93]. Средняя длительность лечения при коротких курсах составила 4,9 дня, при длительных - 8,3 дня. Кратковременное наблюдение за больными продолжалось в среднем 15 дней, долговременное - 31 день. Клиническое разрешение обострений в ранние и поздние сроки не различалось между сравниваемыми группами. Суммарное ОШ для клинического разрешения обострения в ранние сроки составило 0,99 (95\%-ный ДИ - 0,90-1,08), при длительном наблюдении - 1,0 (95\%-ный ДИ - 0,91-1,10). Также 


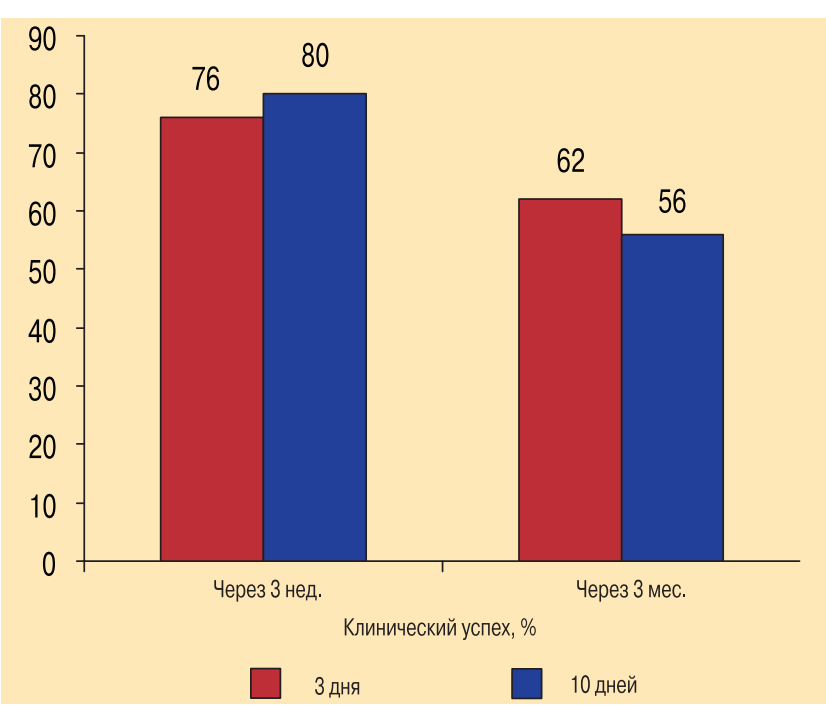

Рис. 5. Сравнение клинического успеха терапии амоксициллином / клавуланатом при обострении ХОБЛ в течение 3 и 10 дней [94]

не было получено различий между группами в бактериологическом разрешении обострения (суммарное ОШ - 1,05; 95\%-ный ДИ - 0,87-1,26).

Таким образом, данный метаанализ продемонстрировал, что при лечении легкого и среднетяжелого обострения ХОБЛ / ХБ короткие курсы антибиотиков столь же эффективны, как и более длительные [93].

Возможность проведения коротких курсов АБТ при обострении ХОБЛ была показана не только для фторхинолонов или макролидов, но и для амоксициллина / клавуланата. В РКИ B.M.Roede et al., включавшем в себя 56 госпитализированных больных с обострением ХОБЛ І типа, по Anthonisen, сравнивалась эффективность терапии амоксициллином / клавуланатом в течение 3 и 10 дней [94]. Исходно все больные в течение 3 сут. получали амоксициллин / клавуланат, а затем, при условии клинического улучшения, были рандомизированы на 2 группы: 1) амоксициллин / клавуланат 625 мг в сутки per os; 2) плацебо в течение 7 дней. Клиническое излечение через 3 нед. от начала терапии было сходным в обеих группах: $76 \%$ vs $80 \%$ соответственно при терапии в течение 3 и 10 дней (различие - 3,8\%; 95\%-ный ДИ - 28-20). Не было различий между группами по клиническому излечению и через 3 мес. - $62 \%$ vs $56 \%$ соответственно (различие - 5,9\%; 95\%-ный ДИ - 23-34 \%; рис. 5). Бактериологическое излечение, улучшение симптомов, использование глюкокортикостероидов, длительность кислородотерапии и госпитализации также оказались сходными в обеих группах. Таким образом, данное исследование показало, что 3-дневная терапия амоксициллином / клавуланатом может быть эффективной у больных с обострением ХОБЛ I типа, по Anthonisen, если начальная терапия приводит к клиническому улучшению.

Результаты исследований эффективности курсов АБТ продолжительностью 3-5 дней следует с осторожностью экстраполировать на больных, госпитализированных в стационар с тяжелым обострением ХОБЛ. Точного на ответа на вопрос о длительности
АБТ при тяжелом обострении ХОБЛ сегодня пока нет. Определить ее можно с помощью мониторинга уровня биомаркеров воспаления. Стратегия инициации и отмены АБТ, основанная на динамике сывороточной концентрации ПКТ, как в уже упомянутом исследовании D.Stolz et al., позволила сократить сроки АБТ у пациентов с тяжелыми респираторными инфекциями (пневмонией) и сепсисом в среднем на 3 дня, без дополнительного риска неудач терапии или осложнений $[46,95,96]$.

\section{Литература}

1. Global Initiative for Chronic Obstructive Lung Disease (GOLD). Global strategy for diagnosis, management, and prevention of chronic obstructive pulmonary disease. NHLBI / WHO workshop report. Last updated 2008. www.goldcopd.org.

2. Burge S., Wedzicha J.A. COPD exacerbations: definitions and classifications. Eur. Respir. J. 2003; 21 (suppl. 41): 46s-53s.

3. Rodriguez-Roisin R. Toward a consensus definition for COPD exacerbations. Chest 2000; 117 (5, suppl. 2): 398S-401S.

4. Stanford R.H., Shen Y., McLaughlin T. Cost of chronic obstructive pulmonary disease in the emergency department and hospital: an analysis of administrative data from 218 US hospitals. Treat. Respir. Med. 2006; 5: 343-349.

5. O'Donnell D.E., Parker C.M. COPD exacerbations: Pathophysiology. Thorax 2006; 61: 354-361.

6. Donaldson G.C., Seemungal T.A.R., Bhowmik A., Wedzicha J.A. Relationship between exacerbation frequency and lung function decline in chronic obstructive pulmonary disease. Thorax 2002; 57: 847-852.

7. Seemungal T.A.R., Donaldson G.C., Paul E.A. et al. Effect of exacerbation on quality of life in patients with chronic obstructive pulmonary disease. Am. J. Respir. Crit. Care Med. 1998; 151: 1418-1422.

8. Miravitlles M., Murio C., Guerrero T. et al. Pharmacoeconomic evaluation of acute exacerbations of chronic bronchitis and COPD. Chest 2002; 121: 1449-1455.

9. Celli B.R., Barnes P.J. Exacerbation of chronic obstructive pulmonary disease. Eur. Respir. J. 2007; 29: 1224-1238.

10. Seneff M.G., Wagner D.P., Wagner R.P. et al. Hospital and 1 -year survival of patients admitted to intensive care units with acute exacerbation of chronic obstructive pulmonary disease. J. A. M. A. 1995; 274: 1852-1857.

11. Zielinski J., MacNee W., Wedzicha J. et al. Causes of death in patients with COPD and chronic respiratory failure. Monaldi Arch. Chest Dis. 1997; 52: 43-47.

12. Veeramachaneni S.B., Sethi S. Pathogenesis of bacterial exacerbations of COPD. COPD 2006; 3: 109-115.

13. White A.J., Gompertz S., Stockley R.A. Chronic obstructive pulmonary disease. 6: The aetiology of exacerbations of chronic obstructive pulmonary disease. Thorax 2003; 58: 73-80.

14. Monso E., Ruiz J., Rosell A. et al. Bacterial infection in chronic obstructive pulmonary disease: A study of stable and exacerbated outpatients using the protected specimen brush. Am. J. Respir. Crit. Care Med. 1995; 152: 1316-1320.

15. Pela R., Marchesani F., Agostinelli C. et al. Airways microbial flora in COPD patients in stable clinical conditions and during exacerbations: A bronchoscopic investigation. Monaldi Arch. Chest Dis. 1998; 53: 262-267. 
16. Sethi S., Evans N., Grant B.J.B., Murphy T.F. New strains of bacteria and exacerbations of chronic obstructive pulmonary disease. N. Engl. J. Med. 2002; 347: 465-471.

17. Soler N., Torres A., Ewig S. et al. Bronchial microbial patterns in severe exacerbations of chronic obstructive pulmonary disease (COPD) requiring mechanical ventilation. Am. J. Respir. Crit. Care Med. 1998; 157: 1498-1505.

18. Fagon J.Y., Chastre J., Trouillet J.L. et al. Characterization of distal bronchial microflora during acute exacerbation of chronic bronchitis. Use of the protected specimen brush technique in 54 mechanically ventilated patients. Am. Rev. Respir. Dis. 1990; 142: 1004-1008.

19. Miravitlles M., Espinosa C., Fernandez-Laso E. et al. Relationship between bacterial flora in sputum and functional impairment in patients with acute exacerbations of COPD. Study Group of Bacterial Infection in COPD. Chest 1999; 116: 40-46.

20. Eller J., Ede A., Schaberg T. et al. Infective exacerbations of chronic bronchitis: relation between bacteriologic etiology and lung function. Chest 1998; 113: 1542-1548.

21. von Hertzen L., Isoaho R., Leinonen M. et al. Chlamydia pneumoniae antibodies in chronic obstructive pulmonary disease. Int. J. Epidemiol. 1996; 25: 658-664.

22. Mogulkoc N., Karakurt S., Isalska B. et al. Acute purulent exacerbation of chronic obstructive pulmonary disease and Chlamydia pneumoniae infection. Am. J. Respir. Crit. Care Med. 1999; 160: 349-353.

23. Diederen B.M., van der Valk P.D., Kluytmans J.A. et al. The role of atypical respiratory pathogens in exacerbations of chronic obstructive pulmonary disease. Eur. Respir. J. 2007; 30: 240-244.

24. Ball P., Harris J.M., Lowson D. et al. Acute infective exacerbations of chronic bronchitis. Q. J. Med. 1995; 88: 61-68.

25. Papi A. et al. Infections and airway inflammation in chronic obstructive pulmonary disease severe exacerbations. Am. J. Respir. Crit. Care Med. 2006; 173 (10): 1114-1121.

26. Seemungal T., Donaldson G.C., Breuer J. et al. Rhinoviruses are associated with exacerbations of COPD. Eur. Respir. J. 1998; 12 (suppl. 28): 298s.

27. Sethi S., Murphy T.F. Infection in the pathogenesis and course of chronic obstructive pulmonary disease. N. Engl. J. Med. 2008; 359: 2355-2365.

28. Hirschmann J.V. Do bacteria cause exacerbations of COPD? Chest 2000; 118: 193-203.

29. Sachs A.P.E., Koeter G.H., Groenier K.H. et al. Changes in symptoms, peak expiratory flow, and sputum flora during treatment with antibiotics of exacerbations in patients with chronic obstructive pulmonary disease in general practice. Thorax 1995; 50: 758-763.

30. Puhan M.A., Vollenweider D., Latshang T. et al. Exacerbations of chronic obstructive pulmonary disease: when are antibiotics indicated? A systematic review. Respir. Res. 2007; 8: 30 .

31. Anthonisen N.R., Manfreda J., Warren C.P.W. et al. Antibiotic therapy in acute exacerbations of chronic obstructive pulmonary disease. Ann. Intern. Med. 1987; 106: 196-204.

32. Nouira S., Marghli S., Belghith M. et al. Once daily oral ofloxacin in chronic obstructive pulmonary disease exacerbations requiring mechanical ventilation: a randomised placebo-controlled trial. Lancet 2001; 358: 2020-2025.

33. Wilson R., Allegra L., Huchon G. et al. Short-term and longterm outcomes of moxifloxacin compared to standard antibiotic treatment in acute exacerbations of chronic bronchitis. Chest 2004; 125: 953-964.
34. Chodosh $S$. Clinical significance of the infection-free interval in the management of acute bacterial exacerbations of chronic bronchitis. Chest 2005; 127: 2231-2236.

35. Adams S., Melo J., Luther M. et al. Antibiotics are associated with lower relapse rates in outpatients with acute exacerbations of chronic obstructive pulmonary disease. Chest 2000; 117: 1345-1352.

36. Roede B.M., Bresser P., Prins J.M. et al. Reduced risk of next exacerbation and mortality associated with antibiotic use in COPD. Eur. Respir. J. 2009; 33: 282-288.

37. Celli B.R., MacNee W. Standards for the diagnosis and treatment of patients with COPD: a summary of the ATS / ERS position paper. Eur. Respir. J. 2004; 23: 932-946.

38. Stockley R.A., O'Brien C., Pye A., Hill S.L. Relationship of sputum color to nature and outpatient management of acute exacerbations of COPD. Chest 2000; 117: 1638-1645.

39. Soler N., Agustí C., Angrill J. et al. Bronchoscopic validation of the significance of sputum purulence in severe exacerbations of chronic obstructive pulmonary disease. Thorax 2007; 62: 29-35.

40. Nseir S., Ader F. Prevalence and outcome of severe chronic obstructive pulmonary disease exacerbations caused by multidrug-resistant bacteria. Curr. Opin. Pulm. Med. 2008; 14: 95-100.

41. Lacoma A., Prat C., Andreo F., Dominguez J. Biomarkers in the management of COPD. Eur. Respir. Rev. 2009; 18 (112): 96-104.

42. Christ-Crain M., Müller B. Biomarkers in respiratory tract infections: diagnostic guides to antibiotic prescription, prognostic markers and mediators. Eur. Respir. J. 2007; 30: $556-573$.

43. Nylen E.S., Snider R.H., Thompson K.A. et al. Pneumonitisassociated hyperprocalcitoninemia. Am. J. Med. Sci. 1996; 312: $12-18$.

44. Boussekey N., Leroy O., Alfandari S. et al. Procalcitonin kinetics in the prognosis of severe community-acquired pneumonia. Intensive Care Med. 2006; 32: 469-472.

45. Becker K.L., Nylen E.S., White J.C. et al. Procalcitonin and the calcitonin gene family of peptides in inflammation, infection, and sepsis: a journey from calcitonin back to its precursors. J. Clin. Endocrinol. Metab. 2004; 89: $1512-1525$.

46. Stolz D., Christ-Crain M., Bingisser R. et al. Antibiotic treatment of exacerbations of COPD. A randomized, controlled trial comparing procalcitonin-guidance with standard therapy. Chest 2007; 131: 9-19.

47. Pepys M.B., Berger A. The renaissance of C-reactive protein. Brit. Med. J. 2001; 322: 4-5.

48. Kolb-Bachofen $V$. A review on the biological properties of C-reactive protein. Immunobiology 1991; 183: 133-145.

49. Ballou S.P., Kushner I. C-reactive protein and the acute phase response. Adv. Intern. Med. 1992; 37: 313-336.

50. Gewurz H., Zhang X., Lint T. Structure and function of the pentraxins. Curr. Opin. Immunol. 1995; 7: 54-64.

51. Shine B., de Beer F.C., Pepys M.B. Solid phase radioimmunoassays for human $\mathrm{C}$-reactive protein. Clin. Chim. Acta 1981; 117: 13-23.

52. Hutchinson W.L. et al. Immunoradiometric assay of circulating C-reactive protein: age-related values in the adult general population. Clin. Chem. 2000; 46: 934-938.

53. Hurst J.R., Donaldson G.C., Perera W.R. Use of plasma biomarkers at exacerbation of chronic obstructive pulmonary disease. Am. J. Respir. Crit. Care Med. 2006; 174: 867-874.

54. Dev D., Sankaran E.W.R., Cunnife J. et al. Value of C-reactive protein in exacerbation of chronic obstructive pulmonary disease. Respir. Med. 1998; 92: 664-667. 
55. Baimakanova G., Zubairova P., Avdeev S., Chuchalin A. Performance of rapid, bedside whole blood C-reactive protein (CRP) test as a diagnostic test for bacterial infection and pneumonia in patients with acute exacerbation of chronic obstructive pulmonary disease. Eur. Respir. J. 2007; 29 (suppl.): 556s.

56. Авдеев С.Н., Баймаканова Г.Е., Зубаирова П.А. Возможности С-реактивного белка в диагностике бактериальной инфекции и пневмонии у больных с обострением хронической обструктивной болезни легких. Уральский мед. журнал 2008; 13: 19-24.

57. Martinez F.J., Han M.K., Flaherty K., Curtis J. Role of infection and antimicrobial therapy in acute exacerbations of chronic obstructive pulmonary disease. Expert. Rev. Antiinfect. Ther. 2006; 4: 101-124.

58. Ram F.S., Rodriguez-Roisin R., Granados-Navarrete A. et al. Antibiotics for exacerbations of chronic obstructive pulmonary disease. Cochrane Database Syst. Rev. (database online). Issue 2; 2006.

59. Grossman R.F. Guidelines for the treatment of acute exacerbations of chronic bronchitis. Chest 1997; 112 (suppl.): 310S-313S.

60. Wilson R., Jones P., Schaberg T. et al. Antibiotic treatment and factors influencing short and long term outcomes of acute exacerbations of chronic bronchitis. Thorax 2006; 61: 337-342.

61. Dimopoulos G., Siempos I.I., Korbila I.P. et al. Comparison of first-line with second-line antibiotics for acute exacerbations of chronic bronchitis: a meta-analysis of randomized controlled trials. Chest 2007; 132: 447-455.

62. Siempos I.I., Dimopoulos G., Korbila I.P. et al. Macrolides, quinolones and amoxicillin / clavulanate for chronic bronchitis: a meta-analysis. Eur. Respir. J. 2007; 29: 1127-1137.

63. Contopoulos-Loannidis D.G., Ioannidis J.P.A., Chewc P., Law J. Meta-analysis of randomized controlled trials on the comparative efficacy and safety of azithromycin against other antibiotics for lower respiratory tract infections. J. Antimicrob. Chemother. 2001; 48: 691-703.

64. Dukes M.N.G., ed. Meyler's side effects of drugs. 13th ed. USA: Elsevier Science; 1996.

65. Козлов Р.С., Сивая О.В., Шпынев К.В. и др. Антибиотикорезистентность Streptococcus pneumoniae в России в 1999-2005 гг: результаты многоцентровых проспективных исследований ПеГАС-I и ПеГАС-II. Клин. микробиол. и антимикроб. химиотер. 2006; 8: 33-47.

66. Hoepelman I.M., Mollers M.J., van Schie M.H. et al. A short (3-day) course of azithromycin tablets versus a 10-day course of amoxycillin-clavulanic acid (co-amoxiclav) in the treatment of adults with lower respiratory tract infections and effects on long-term outcome. Int. J. Antimicrob. Agents 1998; 9: 141-146.

67. Anzueto A., Fisher C.L.Jr., Busman T., Olson C.A. Comparison of the efficacy of extended-release clarithromycin tablets and amoxicillin / clavulanate tablets in the treatment of acute exacerbation of chronic bronchitis. Clin. Ther. 2001; 23: 72-86.

68. Castaldo R.S., Celli B.R., Gomez F. et al. A comparison of 5 -day courses of dirithromycin and azithromycin in the treatment of acute exacerbations of chronic obstructive pulmonary disease. Clin. Ther. 2003; 25: 542-557.

69. Amsden G.W., Baird I.M., Simon S., Treadway G. Efficacy and safety of azithromycin versus levofloxacin in the outpatient treatment of acute bacterial exacerbations of chronic bronchitis. Chest 2003; 123: 772-777.
70. Andre-Alves M.R., Jardim J.R., Silva R.F. et al. Comparison between azithromycin and amoxicillin in the treatment of infectious exacerbation of chronic obstructive pulmonary disease. J. Bras. Pneumol. 2007; 33: 43-50.

71. Rubin B.K. Immunomodulatory properties of macrolides: overview and historical perspective. Am. J. Med. 2004; 117 (9A): $2 \mathrm{~S}-4 \mathrm{~S}$.

72. EUCAST Expert rules in antimicrobial susceptibility testing, version 1, April 2008. www.eucast.org

73. O'Donnell J.A., Gelone S.P. The newer fluoroquinolones. Infect. Dis. Clin. N. Am. 2004; 18: 691-716.

74. Blasi F., Tarsia P., Aliberti S. et al. Highlights on the appropriate use of fluoroquinolones in respiratory tract infections. Pulm. Pharmacol. Ther. 2006; 19: 11-19.

75. Bonfiglio $G$. Is levofloxacin as active as ciprofloxacin against Pseudomonas aeruginosa? Chemotherapy 2001; 47: 239-242.

76. Антибиотикорезистентность в России: Возбудители внебольничных инфекций. www.antibiotic.ru

77. Société de Pathologie Infectieuse de Langue Française. $15^{\text {th }}$ consensus conference about management of lower respiratory tract infections in immunocompetent adult. Med. Mal. Infect. 2006; 36: 235-244.

78. Сидоренко С.В., Козлов С.Н. Группа пенициллинов. В кн.: Практическое руководство по антиинфекционной химиотерапии / под ред. Страчунского Л.С., Белоусова Ю.Б., Козлова С.Н. М.; 2002. 47-55.

79. Дворецкий Л.И., Дубровская Н.В., Грудинина С.А. и др. Клинико-микробиологический мониторинг больных с обострением хронического бронхита, леченных антибактериальными препаратами. Тер. архив 2006; 78 (3): 25-35.

80. Neu H.C., Wilson A.P.R., Gruneberg R.N. Amoxycillin / clavulanic acid: a review of its efficacy in over 38,500 patients from 1979 to 1992. J. Chemother. 1993; 5: 67-93.

81. Карпов О.И. Флемоклав Солютаб - новая лекарственная форма амоксициллина / клавуланата в лечении синусита. Клин. фармакол. и терапия 2006; 15 (4): 1-4.

82. Cortvriendt W.R., Verschoor J.S., Hespe W. Bioavailability study of a new amoxicillin tablet designed for several modes of oral administration. Arzneimittelforschung 1987; 37: 977-979.

83. Sourgens H., Steinbrede H., Verschoor J.S. et al. Bioequivalence study of a novel Solutab tablet formulation of amoxicillin / clavulanic acid versus the originator film-coated tablet. Int. J. Clin. Pharmacol. Ther. 2001; 39: 75-82.

84. Гучев И.А., Козлов Р.С. Безопасность и эффективность различных лекарственных форм амоксициллина / клавулановой кислоты при инфекциях нижних дыхательных путей у взрослых: открытое проспективное рандомизированное исследование. Пульмонология 2008; 2: 73-80.

85. Sethi S., Breton J., Wynne B. Efficacy and safety of pharmacokinetically enhanced amoxicillin-clavulanate at 2,000/ 125 milligrams twice daily for 5 days versus amoxicillinclavulanate at 875 / 125 milligrams twice daily for 7 days in the treatment of acute exacerbations of chronic bronchitis. Antimicrob. Agents Chemother. 2005; 49: 153-160.

86. Álvarez-Sala J.L., Kardos P., Martínez-Beltrán J. et al. Clinical and bacteriological efficacy in treatment of acute exacerbations of chronic bronchitis with cefditoren-pivoxil versus cefuroxime-axetil. Antimicrob. Agents Chemother. 2006; 50: 1762-1767.

87. Chodosh S., DeAbate C.A., Haverstock D. et al. Short-course moxifloxacin therapy for treatment of acute bacterial exacerbations of chronic bronchitis. The Bronchitis Study Group. Respir. Med. 2000; 94: 18-27. 
88. Wilson R., Schentag J.J., Ball P., Mandell L. for the 068 Study Group. A comparison of gemifloxacin and clarithromycin in acute exacerbations of chronic bronchitis and long-term clinical outcomes. Clin. Ther. 2002; 4: 639-652.

89. Sethi S., Fogarty C., Fulambarker A. A randomized, doubleblind study comparing 5 days oral gemifloxacin with 7 days oral levofloxacin in patients with acute exacerbation of chronic bronchitis. Respir. Med. 2004; 98: 697-707.

90. Fogarty C., De Wet R., Mandell L. et al. Five-day telithromycin once daily is as effective as 10 -day clarithromycin twice daily for the treatment of acute exacerbations of chronic bronchitis and is associated with reduced healthcare resource utilization. Chest 2005; 128: 1980-1988.

91. Guay D.R.P. Short-course antimicrobial therapy of respiratory tract infections. Drugs 2003; 63: 2169-2184.

92. Kardas $R$. Patient compliance with antibiotic treatment for respiratory tract infections. J. Antimicrob. Chemother. 2002; 49: 897-903.
93. El Moussaoui R., Roede B.M., Speelman P. et al. Shortcourse antibiotic treatment in acute exacerbations of chronic bronchitis and COPD: a meta-analysis of double-blind studies. Thorax 2008; 63: 415-422.

94. Roede B.M., Bresser P., El Moussaoui R. et al. Three vs 10 days of amoxycillin-clavulanic acid for type 1 acute exacerbations of chronic obstructive pulmonary disease: a randomised, double-blind study. Clin. Microbiol. Infect. 2007; 13: 284-290.

95. Christ-Crain M., Stolz D., Bingisser R. et al. Procalcitonin guidance of antibiotic therapy in community-acquired pneumonia: a randomized trial. Am. J. Respir. Crit. Care Med. 2006; 174: 84-93.

96. Nobre V., Harbarth S., Graf J.-D. et al. Use of procalcitonin to shorten antibiotic treatment duration in septic patients: A randomized trial. Am. J. Respir. Crit. Care Med. 2008; 177: 498-505.

\section{Информация об авторе}

Авдеев Сергей Николаевич - д. м. н., проф., руководитель клинического отдела НИИ пульмонологии ФМБА России; тел: (495) 465-53-64; e-mail: serg_avdeev@list.ru

Поступила 12.04.10 (с) Авдеев С. Н. 2010 удк 616.24-036.12-085.281 
ТОЧНО В ЦЕЛЬ

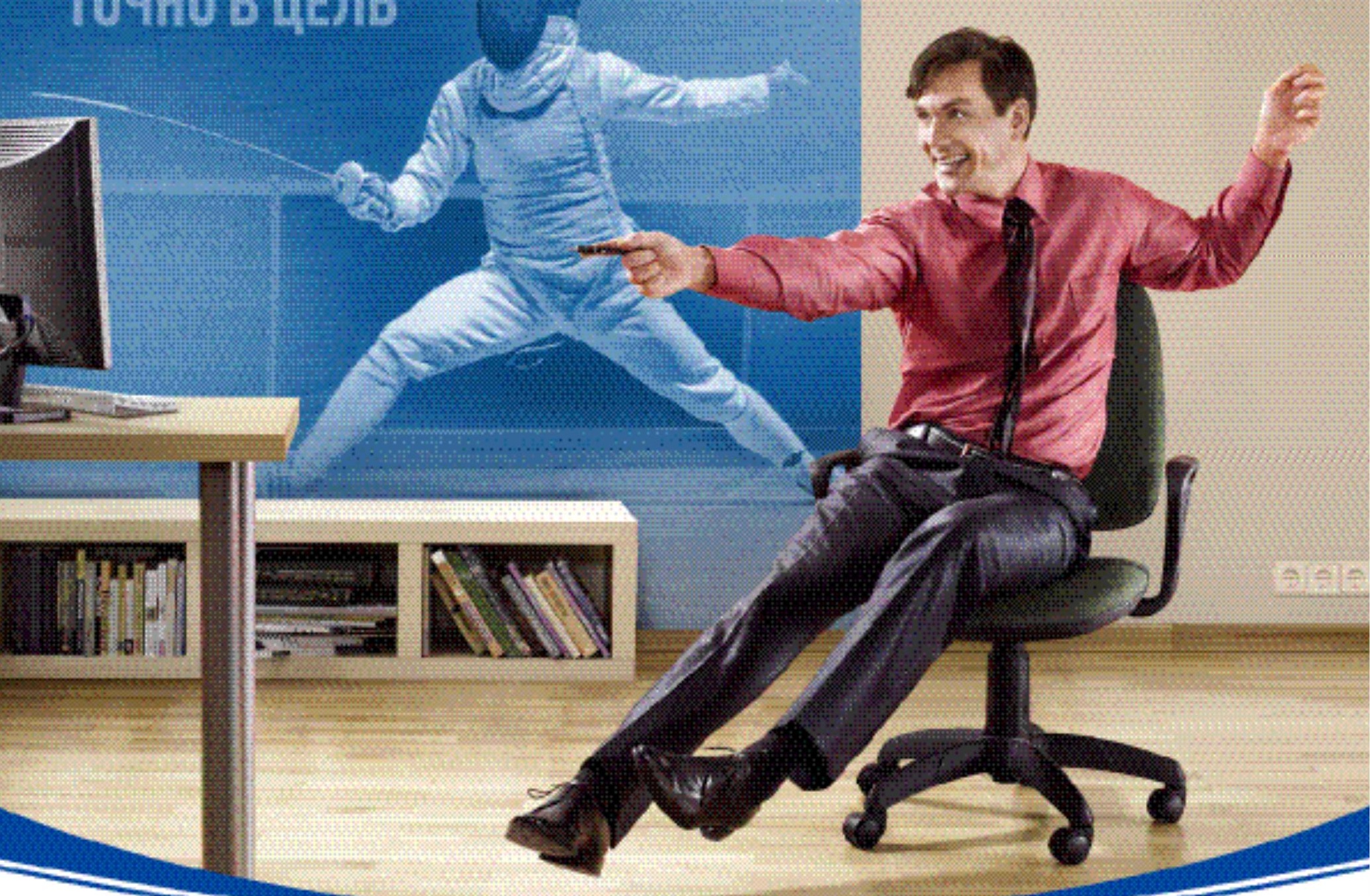

ФЛЕМОКЛАВ СОЛЮТАБ

амокемиилиия / кллавулановая киелоте, 125/31,25 мг; 250/62,5 мг; 500/125 мr; 875/125 мr
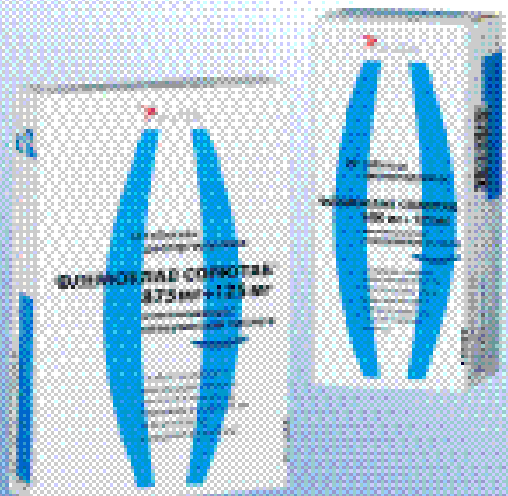
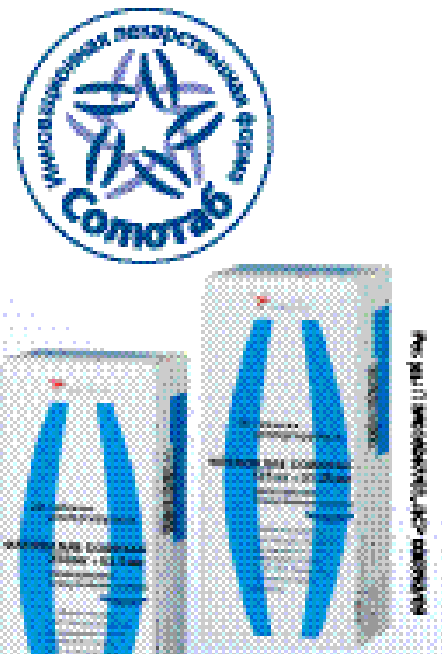

- Защищенный аминопенициллин в инновационной лекарственной форме

- Лекарственная форма Солютаб обеспечивает стабильно высокую биодоступность амоксициллина и минимальную вариабельность всасывания клавулановой кислоты'

- Достоверно снижает частоту нежелательных реакций со стороны ЖКТ, в том числе антибиотик-ассоциированной диареи ${ }^{2}$ 